\title{
Manipulations in HIWI level exerts influence on the proliferation of human non-small cell lung cancer cells
}

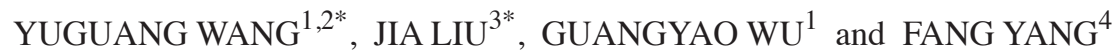

\begin{abstract}
${ }^{1}$ Department of Magnetic Resonance Imaging, Zhongnan Hospital of Wuhan University, Wuhan, Hubei 430071;
${ }^{2}$ Department of Magnetic Resonance Imaging, Second Affiliated Hospital of Inner Mongolia Medical University, Hohhot, Inner Mongolia 010030; ${ }^{3}$ Department of Stomatology, Affiliated Hospital of Inner Mongolia Medical University, Hohhot, Inner Mongolia 010050; ${ }^{4}$ Department of Physiology, Basic Medical School of Wuhan University,
\end{abstract} \\ Wuhan, Hubei 430071, P.R. China
}

Received December 8, 2014; Accepted December 21, 2015

DOI: $10.3892 /$ etm.2016.3106

\begin{abstract}
Lung cancer is the leading cause of cancer-associated mortality worldwide, although molecular imaging techniques, including fludeoxyglucose positron emission tomography, have markedly improved the diagnosis of lung cancer. HIWI is a member of the human piwi family, members of which are known for their roles in RNA silencing. HIWI has been shown to serve a crucial function in stem cell self-renewal, and previous studies have reported HIWI overexpression in lung cancers. Furthermore, HIWI has been proposed to regulate the maintenance of cancer stem cell populations in lung cancers. The present study investigated the mRNA and protein expression levels of HIWI in non-small cell lung cancer (NSCLC) specimens harvested from 57 patients, using reverse transcription-quantitative polymerase chain reaction and western blot analysis, respectively. Subsequently, the HIWI expression level was manipulated using gain-of-function and loss-of-function strategies, and the role of HIWI in the proliferation of human A549 NSCLC cells was investigated using Cell Counting Kit-8 and colony formation assays. The mRNA and protein expression levels of HIWI were significantly upregulated in the intratumor NSCLC specimens, as compared with the peritumor specimens. Furthermore, the mRNA and protein expression levels of HIWI in A549 cells were successfully manipulated using the two strategies. Overexpression and knockout of HIWI were associated with the promotion and inhibition of A549 cell proliferation, respectively. The results of the present study suggested that HIWI is overexpressed in NSCLC tissues and demonstrated that upregulation of HIWI
\end{abstract}

Correspondence to: Dr Guangyao Wu, Department of Magnetic Resonance Imaging, Zhongnan Hospital of Wuhan University, 169 Donghu Road, Wuchang, Wuhan, Hubei 430071, P.R. China E-mail: guangyowu@163.com

*Contributed equally

Key words: HIWI, proliferation, non-small cell lung cancer, A549 may promote the growth of lung cancer cells; thus suggesting that HIWI may have an oncogenic role in lung cancer.

\section{Introduction}

Lung cancer is the leading cause of cancer-associated mortality worldwide (1), among which non-small cell lung cancer (NSCLC) accounts for $~ 80 \%$ of all cases of lung cancer (2). The incidence of NSCLC in China has markedly increased over the past 5 years (3). At present, numerous clinical and molecular prognostic factors are considered in order to tailor therapies to particular subgroups of patients; however, treatment responses are routinely assessed by serial measurements of tumour sizes prior to and following treatment (4). Molecular imaging, which is a research and clinical tool that was developed $>30$ years ago (5), has markedly improved the diagnosis and the treatment of lung cancers. Previous studies have suggested the superior prognostic value of fludeoxyglucose positron emission tomography, as compared with computed tomography, and it has exhibited enhanced sensitivity for the evaluation of therapeutic effects (6-8). However, NSCLC is typically diagnosed at the advanced stages, leading to a poor prognosis in China (9).

The hiwi gene, which is a human homologue of the piwi family, is located at $12 \mathrm{q} 24.33$ and encodes the $98.5 \mathrm{kDa}$ HIWI protein (10). The piwi family has been shown to have an important role in stem cell self-renewal in diverse organisms, including jellyfish, Caenorhabditis elegans, Drosophila melanogaster, zebrafish, mice and humans (11-13). HIWI is typically expressed in $\mathrm{CD}_{3} 4^{+}$hematopoietic progenitor cells, although not in the more differentiated cell populations (14). Furthermore, HIWI has been shown to be highly expressed in numerous human cancer types $(11,15)$, and abnormal HIWI expression levels have been associated with a poor prognosis in various human malignant tumors, including human esophageal squamous cell carcinoma (16), human adenocarcinoma of the pancreas (15), human gastric cancer (11), and colorectal cancer (17). In addition, a previous study demonstrated that silencing of the HIWI gene was able to decrease the proliferation and promote the apoptosis of lung cancer tumor stem cells (18), and it was suggested that the hiwi gene may be a key regulator in the maintenance of cancer stem cell (CSC) populations in lung cancers $(19,20)$. Therefore, 
HIWI has been implicated in the tumorigenesis of lung cancers and may be a potential target for novel cancer therapies.

The present study aimed to investigate whether HIWI is overexpressed in NSCLC specimens, and the effects of manipulating the expression levels of HIWI on the proliferation of a human A549 NSCLC cell line.

\section{Materials and methods}

NSCLC specimens, cell lines and culture. The present study was approved by the Ethics Committee of the Zhongnan Hospital of Wuhan University (Wuhan, China). A total of 57 patients with NSCLC (average age, 64.3 years; 40 male and 17 female) at the Zhongnan Hospital of Wuhan University were enrolled in the present study between February 2008 and September 2013. Informed consent was obtained from all patients. A total of 57 intratumor specimens and 57 peritumor specimens (control; $\geq 10 \mathrm{~mm}$ from the tumor edge) were harvested during surgical resection $(10 \mathrm{~mm})$ from the patients prior to treatment with radiotherapy and chemotherapy. The specimens were immediately frozen in liquid nitrogen and stored at $-80^{\circ} \mathrm{C}$. The clinico-pathological data of the patients was recorded prospectively, including the age at diagnosis, tumor size, axillary lymph node metastasis and histological grade (21). Human NSCLC A549 cells were purchased from the American Type Culture Collection (Manassas, VA, USA) and were cultured in Gibco Dulbecco's modified Eagle's medium (DMEM; Thermo Fisher Scientific, Inc., Waltham, MA, USA) supplemented with $10 \%$ fetal bovine serum (Sijiqing Bio-technology, Co. Ltd., Hangzhou, China) at $37^{\circ} \mathrm{C}$ in a humidified atmosphere containing $5 \% \mathrm{CO}_{2}$.

RNA extraction and reverse transcription-quantitative polymerase chain reaction $(R T-q P C R)$. In order to evaluate the mRNA expression levels of HIWI, total RNA from the intratumor and peritumor specimens and A549 cells was extracted using TRIzol ${ }^{\circledR}$ reagent (Invitrogen; Thermo Fisher Scientific, Inc.), according to the manufacturer's protocol, and supplemented with $1 \mu 1$ RNase inhibitor (Takara Bio, Inc., Otsu, Japan). RT-qPCR was conducted using a SYBR PrimeScript RT-qPCR kit (Takara Bio, Inc.) according to the manufacturer's instructions with a $1 \mu$ l RNA template in a LightCycler $^{\circledR} 480$ Instrument II thermal cycler (Roche Diagnostics $\mathrm{GmbH}$, Mannheim, Germany). The thermal cycling conditions were as follows: $42^{\circ} \mathrm{C} \mathrm{For} 5 \mathrm{~min}$, and $95^{\circ} \mathrm{C}$ for $10 \mathrm{sec}$ for the reverse transcription, and 40 cycles of $95^{\circ} \mathrm{C}$ for $5 \mathrm{sec}$ and at $60^{\circ} \mathrm{C}$ for $20 \mathrm{sec}$ for the PCR reaction. The primer sets for HIWI and $\beta$-actin genes were synthesized by Sangon Biotech, Co., Ltd. (Shanghai, China) according to previously reported sequences (22). The primer sequences were as following: HIWI forward, 5'-AGC ACTAACCATTTCCGGCTG-3' and reverse, 5'-TATAGT CAATGTGATACTGAT-3'; and $\beta$-actin forward, 5'-GTACCC TGGCATTGCCGACA-3' and reverse, 5'-CTCGTCATACTC CTGCTTGCT-3'. The mRNA expression levels of HIWI were normalized against those of $\beta$-actin, and were expressed as the fold-change over control, as determined using the $2^{-\Delta \Delta \mathrm{Cq}}$ method (23).

Western blot analysis. NSCLC specimens were homogenized and subjected to protein isolation using a cell lysis reagent (V8571; Promega Corporation, Madison, WI, USA), according to the manufacturer's protocol. Protein samples $(30 \mu \mathrm{g})$ were quantified using a BCA Protein Assay Reagent Kit (Pierce Biotechnology, Inc., Rockford, IL, USA) separated by $10 \%$ sodium dodecyl sulfate-polyacrylamide gel electrophoresis [GenScript (Nanjing) Co., Ltd., Nanjing, China] with a loading quantity of 50-90 $\mu \mathrm{g}$, and transferred to a polyvinylidene fluoride membrane (EMD Millipore, Billerica, MA, USA), which was blocked using Tris-buffered saline solution (Takara Bio, Inc.) containing 5\% milk. Subsequently, the membranes were incubated with polyclonal rabbit anti-HIWI polyclonal antibody (1:300; 701177; Thermo Fisher Scientific Inc.) or anti- $\beta$-actin (1:00; 100162-RP02-100; Sino Biological, Inc., Beijing, China) at $37^{\circ} \mathrm{C}$ for $1 \mathrm{~h}$, followed by incubation with peroxidase-conjugated secondary antibody (1:500; PA1-096; Pierce Biotechnology, Inc., Rockford, IL, USA) at $37^{\circ} \mathrm{C}$ for $45 \mathrm{~min}$. Antibody complexes were visualized using the Enhanced Chemiluminescence Detection system (GE Healthcare Life Sciences, Chalfont, UK), according to the manufacturer's protocol.

Manipulation of HIWI expression levels in A549 cells. In order to overexpress HIWI in A549 cells, wild-type HIWI and enhanced green fluorescence protein (EGFP) coding sequences were amplified and cloned into the eucaryotic expression pcDNA3.1 (+) vector (Invitrogen; Thermo Fisher Scientific, Inc.). A self-cleaving $2 \mathrm{~A}$ linker sequence was inserted between the HIWI and EGFP coding sequences, which enabled the genes to be transcribed into a single mRNA sequence, but translated into two separate proteins (24). The HIWI-2A-EGFP-pcDNA3.1 (+) or control CAT-2A-EGFP-pcDNA3.1 (+) vectors were transfected into A549 cells using Lipofectamine 2000 (Invitrogen; Thermo Fisher Scientific, Inc.). The HIWI+EGFP positive cell clones [A549 HIWI (+)] and the CAT+EGFP positive cell clones (A549 control) were selected in the presence of $1.2 \mathrm{mg} / \mathrm{ml}$ G418 (Sigma-Aldrich, St. Louis, MO, USA), and maintained in DMEM containing $500 \mu \mathrm{g} / \mathrm{ml}$ G418. In order to downregulate HIWI expression levels, Stealth RNAi ${ }^{\mathrm{TM}}$ siRNA sequences (Thermo Fisher Scientific, Inc.) were used, according to the manufacturer's protocol. Briefly, small interfering (si)RNAs [Genscript (Nanjing) Co., Ltd.] specifically targeting HIWI, including siRNA-HIWI 1, siRNA-HIWI 2 or siRNA-Con (10 nM) were transfected into A549 HIWI (+) cells using Lipofectamine 2000.

Cell counting, Cell Counting Kit (CCK)-8 and colony formation assays. The cell counting assay was conducted using a method described in a previous study (25). Briefly, 1,000 cells/well ( $\sim 85 \%$ confluence) were seeded into 6 -well plates and were incubated for $24,48,72$ or $96 \mathrm{~h}$ at $37^{\circ} \mathrm{C}$, followed by trypsinization with $0.25 \%$ trypsin (Amresco LLC, Solon, OH, USA). The number of viable cells was counted in a hemocytometer (Reichert Technologies, Buffalo, NY, USA) following Trypan blue staining (Sigma-Aldrich). For the proliferation assay, A549 HIWI (+) and A549 control cells were treated with $20 \mu \mathrm{M}$ cisplatin (Sigma-Alrdich) for 12, 24, or $48 \mathrm{~h}$, and were subsequently incubated with CCK-8 assay solution (Dojindo Molecular Technologies, Inc., Kumamoto, Japan). The absorbance of each well was detected at $450 \mathrm{~nm}$ following the development of coloration, as determined visually using a spectrophotometer (Crystaleye; Olympus Corporation, Tokyo, Japan). For the colony formation assay, 200 cells from each group were 
A

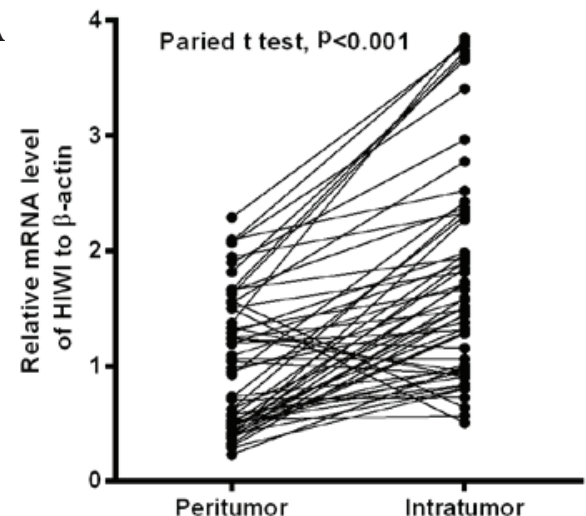

B
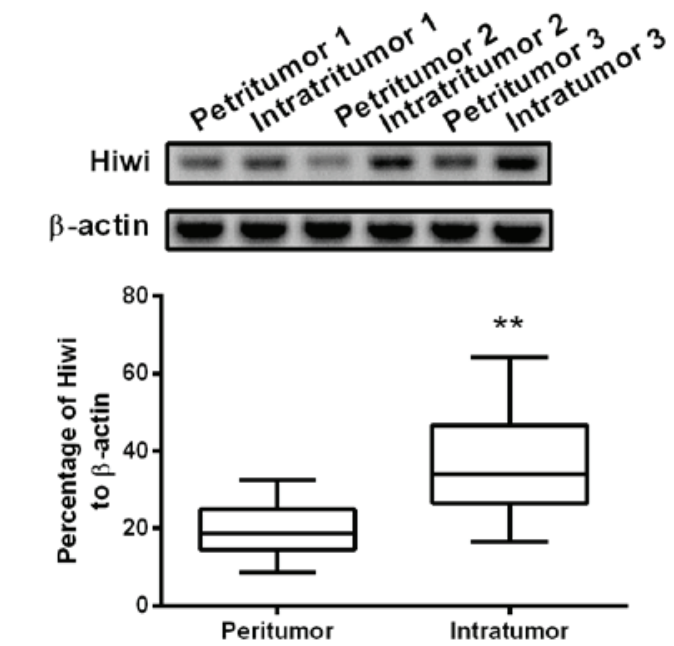

Figure 1. Overexpression of HIWI in non-small cell lung cancer (NSCLC) specimens from 57 patients. (A) Relative mRNA expression levels of HIWI to $\beta$-actin in the intra- $(\mathrm{n}=57)$ and peri-tumor $(\mathrm{n}=57)$ tissues were determined using the reverse transcription-quantitative polymerase chain reaction assay, (B) Relative protein expression levels of HIWI in the NSCLC intratumor specimens $(n=15)$ vs. the peritumor specimens $(n=15)$ were determined using western blotting. ${ }^{* *} \mathrm{P}<0.01$ vs. the peritumor specimens. ns, no significance.
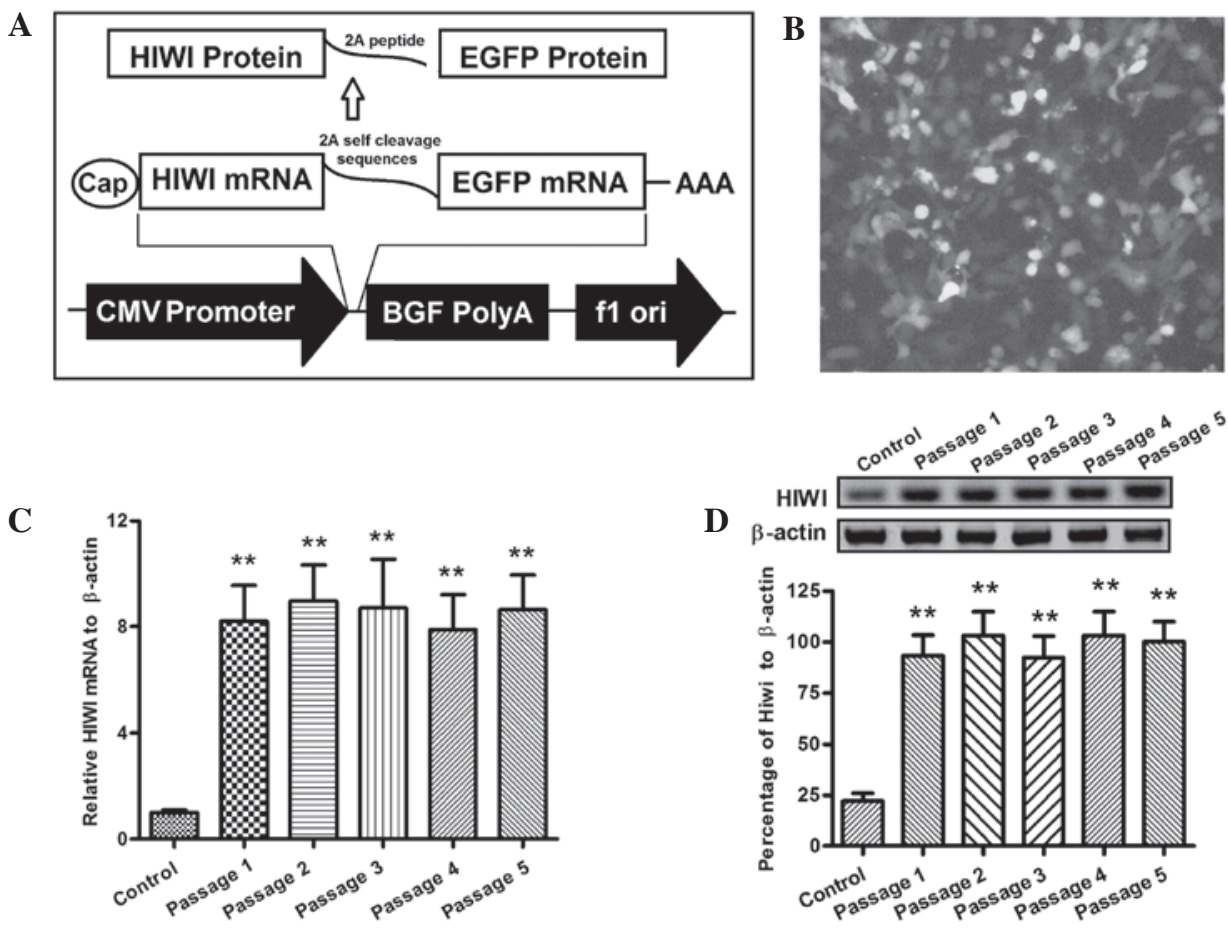

Figure 2. HIWI overexpression was stabilized in the HIWI and EGFP co-expressing A549 HIWI (+) cells. (A) A sketch map of the HIWI and EGFP genes joined with a self-cleaving 2A linkage sequence. (B) The EGFP-positive A549 HIWI (+) cells were selected under G418 pressure. The (C) mRNA and (D) protein expression levels of HIWI in the A549 HIWI (+) cells were stabilized following serial passages, as demonstrated using reverse transcription-quantitative polymerase chain reaction and western blotting, respectively. ${ }^{* *} \mathrm{P}<0.01 \mathrm{vs}$. the A549 control cells. Each result was the average of three independent results. EGFP, enhanced green fluorescent protein; CMV promoter, cytomegalovirus promoter.

seeded into a 12-well plate, with or without siRNA transfection. Following $48 \mathrm{~h}$, the cells were stained with $0.5 \%$ crystal violet solution (Sigma-Aldrich). The number of colonies were counted directly on the plate.

Statistical analysis. Statistical analyses were conducted using the GraphPad Prism software (version 5.0; GraphPad Software, Inc., La Jolla, CA, USA). The mRNA and protein expression levels of HIWI and the cell and colony numbers were compared between the two groups using the Student's $t$-test. $\mathrm{P}<0.05$ was considered to indicate a statistically significant difference.

\section{Results}

HIWI is upregulated in NSCLC specimens. The mRNA and protein expression levels of HIWI in NSCLC tissues were determined using RT-qPCR and western blot analysis, respectively. The mRNA expression levels of HIWI were significantly 
A

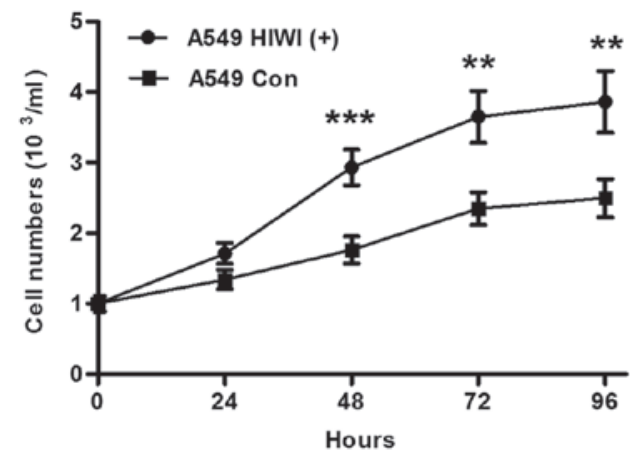

C
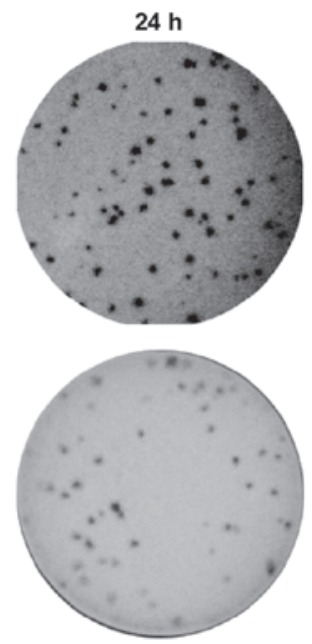

$48 \mathrm{~h}$

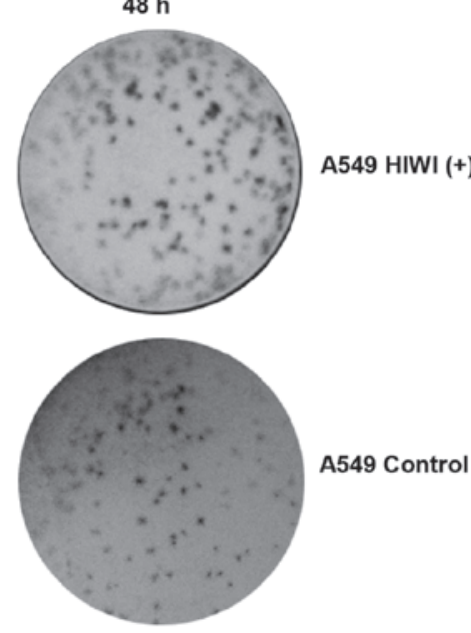

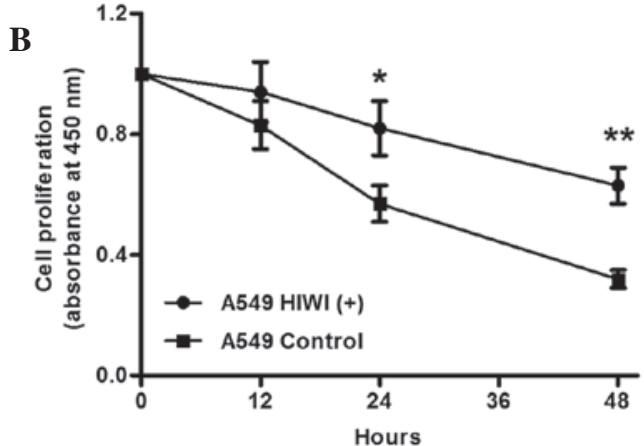

D

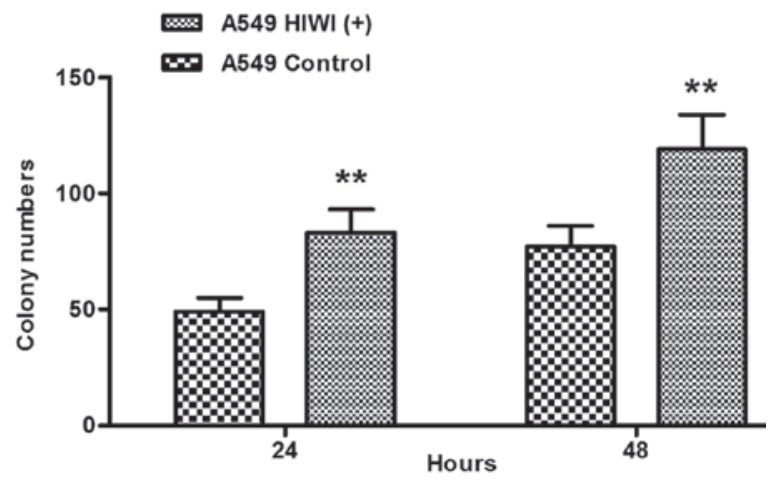

Figure 3. Overexpression of HIWI promotes the proliferation of human non-small cell lung cancer A549 HIWI (+) cells. (A) A significantly higher proliferation rate was detected for the A549 HIWI (+) cells, as compared with the A549 control cells, at 24, 48, 72 and 96 h post-inoculation (10³ cells/ml). (B) The rate of cell death was significantly reduced in the A549 HIWI (+) group following $20 \mu \mathrm{M}$ cisplatin treatment for 12,24 and $48 \mathrm{~h}$, as compared with the A549 control group (C and D). Differences in colony formation between the A549 HIWI (+) and A549 control cells. Each value is an average of three independent tests. ${ }^{*} \mathrm{P}<0.05,{ }^{* *} \mathrm{P}<0.01$ and ${ }^{* * *} \mathrm{P}<0.001$ vs. the A549 control group.

upregulated in the intratumor specimens from 57 patients with NSCLC, as compared with the peritumor specimens from the same patients [mean difference $=0.7642 ; 95 \%$ confidence interval (CI), 0.5695-0.9590; R² 0.5249; P<0.01; Fig. 1A]. Similarly, the protein expression levels of HIWI in 15 intratumor specimens were significantly increased, as compared with 15 peritumor specimens $(\mathrm{P}<0.01$; Fig. 1B). These results suggest that HIWI is upregulated in NSCLC specimens.

HIWI promotes $A 549$ cell proliferation. In order to evaluate the effects of HIWI overexpression on the proliferation of A549 NSCLC cells, growth curves for A549 HIWI (+) cells and A549 control cells were constructed as indicated by Fig. 2A. The GFP-positive cell clone was selected (Fig. 2B) and high expression levels of HIWI mRNA (Fig. 2C) and protein (Fig. 2D) were detected. The CCK-8 assay indicated that the proliferation rate of A549 HIWI (+) cells was significantly higher between 24 and $96 \mathrm{~h}$ post-inoculation, as compared with the A549 control cells $(\mathrm{P}<0.001$ and $\mathrm{P}<0.01$, respectively; Fig. 3A). Furthermore, in the presence of cisplatin, the proliferation rate was significantly higher in the A549 HIWI (+) group, as compared with the A549 control group $(\mathrm{P}<0.05$ and $\mathrm{P}<0.01$ at 24 and 48 h post-inoculation, respectively; Fig. 3B). The growth difference between the A549 HIWI (+) and A549 control cells was reconfirmed by the colony formation assay; significantly more colonies were formed by the A549 HIWI (+) cells at 24 and $48 \mathrm{~h}$ post-inoculation, as compared with the A549 control cells ( $\mathrm{P}<0.01$; Fig. $3 \mathrm{C}$ and D). These results suggest that overexpression of HIWI in vitro promotes the proliferation of human A549 NSCLC cells.

HIWI knockdown by siRNAs blocks the HIWI overexpression-induced promotion of A549 NSCLC cell proliferation. The ability of HIWI overexpression to promote the proliferation of A549 cells was re-evaluated using hiwi-specific siRNA transfection. Briefly, HIWI expression was knocked-down by transfecting hiwi-specific siRNAs into the A549HIWI (+) cells. Significantly reduced mRNA and protein expression levels of HIWI were detected in siRNA-HIWI 1- or siRNA-HIWI 2-transfected A549 HIWI (+) cells, as compared with the siRNA-con transfected cells $(\mathrm{P}<0.01$; Fig. $4 \mathrm{~A}$ and $\mathrm{B})$. Subsequently, the effects of HIWI knockdown on the rate of proliferation of A549 NSCLC cells was analyzed. The CCK- 8 assay indicated that cell proliferation was significantly reduced in the siRNA-HIWI 1- and siRNA-HIWI 2-transfected cells $(\mathrm{P}<0.05$ and $\mathrm{P}<0.01$ at 24 and 48 h post-transfection, respectively; Fig. 4C). In addition, the number of colonies formed was significantly reduced in the siRNA-HIWI 1- and siRNA-HIWI 2-transfected groups, as compared with the siRNA-con transfected group $(\mathrm{P}<0.01$; Fig. 4D and E). These results suggest that HIWI overexpression may promote the proliferation of NSCLC A549 cells. 
A

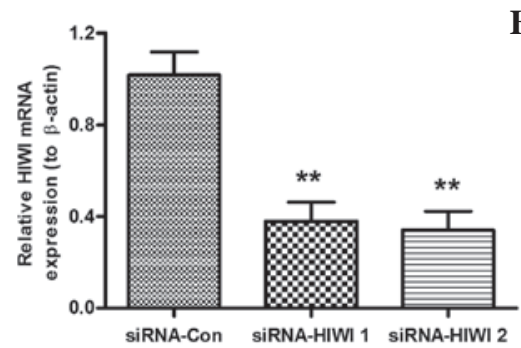

C

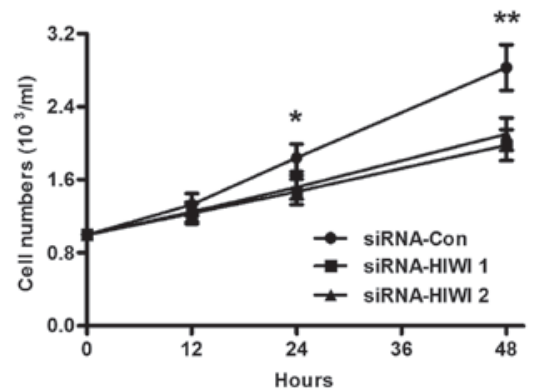

$\mathbf{E}$

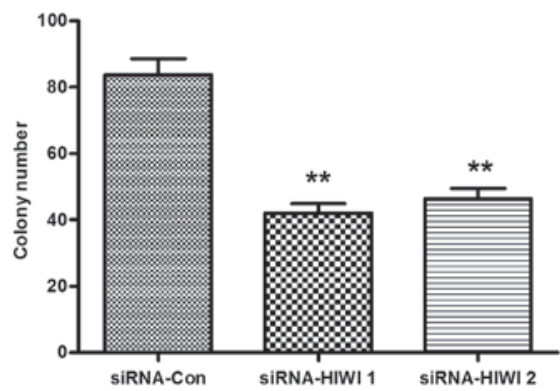

B

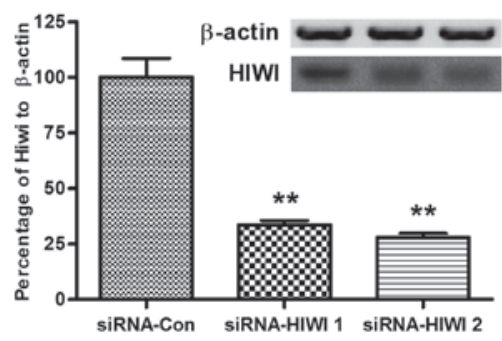

D

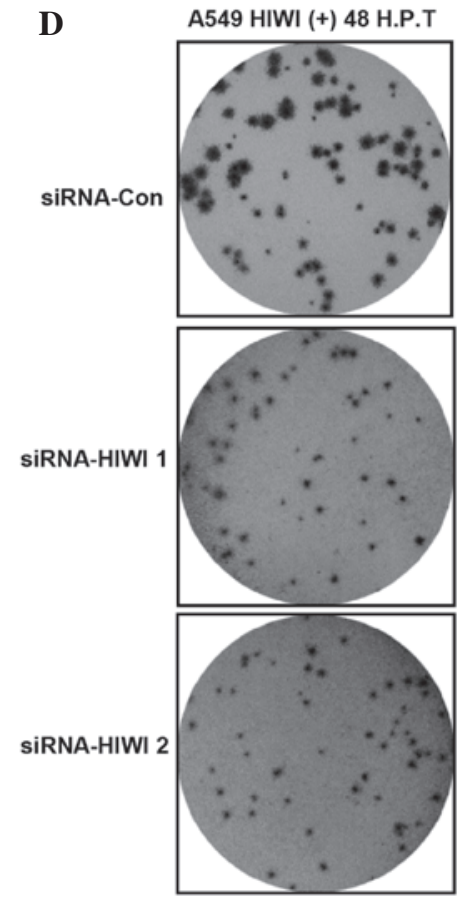

Figure 4. Knockdown of hiwi by siRNA transfection inhibited the proliferation of A549 HIWI (+) cells. (A) mRNA and (B) protein expression levels of HIWI were significantly downregulated in the A549 HIWI (+) cells at $24 \mathrm{~h}$ following transfection with siRNA-HIWI 1 and siRNA-HIWI 2, as compared with the cells transfected with siRNA-Con. (C and D) The proliferation of A549 HIWI (+) cells transfected with siRNA-HIWI 1 or siRNA-HIWI 2 was significantly reduced, as compared with the cells transfected with siRNA-Con, as demonstrated using the (C) cell counting kit-8 assay and (D) the colony formation assay. (E) The graph indicates the colony number of cells transfected with siRNA-Con, siRNA-HIWI 1 or siRNA-HIWI 2. Experiments were performed independently in triplicate. ${ }^{*} \mathrm{P}<0.05$ and ${ }^{* *} \mathrm{P}<0.01$ vs. the siRNA-Con group. siRNA, small interfering RNA.

\section{Discussion}

HIWI is a member of Argonaute (Ago) family, which exert RNase activity similar to RNase H endonuclease (26). Previous studies have reported that the piwi gene family, including hiwi, may be associated with a novel class of small RNAs, called 'piwi-interacting RNAs' (piRNAs). piRNAS have previously been associated with mammalian spermatogenesis (11,13,27-29), and are a type of regulatory small non-coding RNA (ncRNA) (30-32). In order to perform their functions, small ncRNAs are incorporated into Ago complexes to form highly specific small-RNA-binding modules in RNA-silencing pathways $(33,34)$. HIWI has previously been shown to be highly expressed in numerous types of human cancers, and HIWI overexpression has been associated with a poor prognosis $(11,5-7)$. In addition, HIWI gene silencing was shown to decrease the proliferation and promote the apoptosis of lung cancer tumor stem cells (8). Furthermore, it was proposed that the hiwi gene may be a key regulator in the maintenance of CSC populations in lung cancers $(9,20)$. However, it is currently unclear how this ribonucleoprotein-like molecule may promote tumorigenesis.
Yang et al demonstrated that the inhibition of HIWI expression was able to significantly reduce tumor growth in a xenograft mouse model (35). Furthermore, immunohistochemical analyses suggested that downregulation of HIWI was associated with a reduced number of aldehyde dehydrogenase (ALDH)-1 positive cells in xenograft tumor samples (36). Since ALDH-1 is a marker of lung cancer stem cells (37), it has been hypothesized that the use of small hairpin RNA-mediated hiwi gene silencing may decrease the number of lung cancer stem cells and suppress tumor growth in nude mice. Therefore, HIWI may have a crucial role in the regulation of lung cancer stem cell growth.

The present study detected HIWI overexpression in NSCLC tissue samples at the mRNA and protein level; significantly higher HIWI mRNA and protein expression levels were detected in the intratumor specimens, as compared with the peritumor specimens. Gain-of-function and loss-of-function strategies were adopted in order to investigate the effects of hiwi overexpression on A549 NSCLC cell proliferation. Notably, the mRNA and protein expression levels of HIWI were significantly higher in the A549 HIWI (+) cells, and this 
was stable following serial passages. The CCK- 8 and colony formation assays suggested that overexpression of HIWI promoted A549 cell proliferation, and this was confirmed by RNAi, in which the knock-out of HIWI by siRNAs resulted in attenuation of the HIWI-associated promotion of A549 cell proliferation.

In conclusion, the present study demonstrated that HIWI was overexpressed in NSCLC specimens, and identified a positive correlation between the expression levels of HIWI and the proliferation of NSCLC A549 cells, using gain-of-function and loss-of-function strategies. Therefore, the results of the present study suggested that HIWI may have an oncogenic role in the tumorigenesis of NSCLC; however, the mechanisms underlying the promotion of NSCLC cell proliferation by HIWI requires further investigation.

\section{Acknowledgements}

The present study was supported by the Natural Science Foundation of China (grant nos. 81171315 and 81227902).

\section{References}

1. Jemal A, Siegel R, Xu J and Ward E: Cancer statistics, 2010. CA Cancer J Clin 60: 277-300, 2010.

2. Spira A and Ettinger DS: Multidisciplinary management of lung cancer. N Engl J Med 350: 379-392, 2004.

3. Yang L, Parkin DM, Ferlay J, Li L and Chen Y: Estimates of cancer incidence in China for 2000 and projections for 2005. Cancer Epidemiol Biomarkers Prev 14: 243-250, 2005.

4. Vielh P, Spano JP, Grenier J, Le Chevalier T and Soria JC: Molecular prognostic factors in resectable non-small cell lung cancer. Crit Rev Oncol Hematol 53: 193-197, 2005.

5. Herschman HR: Molecular imaging: Looking at problems, seeing solutions. Science 302: 605-608, 2003.

6. Erasmus JJ, Rohren E and Swisher SG: Prognosis and reevaluation of lung cancer by positron emission tomography imaging. Proc Am Thorac Soc 6: 171-179, 2009.

7. Hoekstra CJ, Stroobants SG, Smit EF, Vansteenkiste J, van Tinteren H, Postmus PE, Golding RP, Biesma B, Schramel FJ, van Zandwijk N, et al: Prognostic relevance of response evaluation using [18F]-2-fluoro-2-deoxy-D-glucose positron emission tomography in patients with locally advanced non-small-cell lung cancer. J Clin Oncol 23: 8362-8370, 2005.

8. Weber WA, Petersen V, Schmidt B, Tyndale-Hines L, Link T, Peschel C and Schwaiger M: Positron emission tomography in non-small-cell lung cancer: Prediction of response to chemotherapy by quantitative assessment of glucose use. J Clin Oncol 21: 2651-2657, 2003.

9. Yang J, Zhu J, Zhang YH, Chen YS, Ding LL, Kensler TW and Chen JG: Lung cancer in a rural area of China: Rapid rise in incidence and poor improvement in survival. Asian Pac J Cancer Prev 16: 7295-7302, 2015.

10. Qiao D, Zeeman AM, Deng W,Looijenga LH and Lin H: Molecular characterization of hiwi, a human member of the piwi gene family whose overexpression is correlated to seminomas. Oncogene 21: 3988-3999, 2002

11. Liu X, Sun Y, Guo J, Ma H, Li J, Dong B, Jin G, Zhang J, Wu J, Meng L and Shou C: Expression of hiwi gene in human gastric cancer was associated with proliferation of cancer cells. Int J Cancer 118: 1922-1929, 2006.

12. Cox DN, Chao A, Baker J, Chang L, Qiao D and Lin H: A novel class of evolutionarily conserved genes defined by piwi are essential for stem cell self-renewal. Genes Dev 12: 3715-3727, 1998.

13. Hutvagner G and Simard MJ: Argonaute proteins: Key players in RNA silencing. Nat Rev Mol Cell Biol 9: 22-32, 2008.

14. Sharma AK, Nelson MC, Brandt JE, Wessman M, Mahmud N, Weller KP and Hoffman R: Human CD34 (+) stem cells express the hiwi gene, a human homologue of the Drosophila gene piwi. Blood 97: 426-434, 2001
15. Grochola LF, Greither T, Taubert H, Möller P, Knippschild U, Udelnow A, Henne-Bruns D and Würl P: The stem cell-associated Hiwi gene in human adenocarcinoma of the pancreas: Expression and risk of tumour-related death. Br J Cancer 99: 1083-1088, 2008.

16. He W, Wang Z, Wang Q, Fan Q, Shou C, Wang J, Giercksky KE, Nesland JM and Suo Z: Expression of HIWI in human esophageal squamous cell carcinoma is significantly associated with poorer prognosis. BMC Cancer 9: 426, 2009.

17. Oh SJ, Kim SM, Kim YO and Chang HK: Clinicopathologic implications of PIWIL2 expression in colorectal cancer. Korean J Pathol 46: 318-323, 2012.

18. Liang D, Fang Z, Dong M, Liang C, Xing C, Zhao J and Yang Y: Effect of RNA interference-related $\mathrm{HiWi}$ gene expression on the proliferation and apoptosis of lung cancer stem cells. Oncol Lett 4: 146-150, 2012.

19. Taubert H, Greither T, Kaushal D, Würl P, Bache M, Bartel F, Kehlen A, Lautenschläger C, Harris L, Kraemer K, et al: Expression of the stem cell self-renewal gene Hiwi and risk of tumour-related death in patients with soft-tissue sarcoma. Oncogene 26: 1098-1100, 2007.

20. Siddiqi S, Terry M and Matushansky I: Hiwi mediated tumorigenesis is associated with DNA hypermethylation. PLoS One 7: e33711, 2012

21. Greaves SM, Brown K, Garon EB and Garon BL: The new staging system for lung cancer: Imaging and clinical implications. J Thorac Imaging 26: 119-131, 2011.

22. Zhao YM, Zhou JM, Wang LR, He HW, Wang XL, Tao ZH, Sun HC, Wu WZ, Fan J, Tang ZY and Wang L: HIWI is associated with prognosis in patients with hepatocellular carcinoma after curative resection. Cancer 118: 2708-2717, 2012.

23. Livak KJ and Schmittgen TD: Analysis of relative gene expression data using real-time quantitative PCR and the 2(-Delta Delta C(T)) Method. Methods 25: 402-408, 2001

24. Cheng M, Liu F, Peng Y, Chen J, Chen G, Xiao L and Liu H: Construction of a CTGF and RFP-coexpressed renal tubular epithelial cell and its application on evaluation of CTGF-specific siRNAs on epithelial-mesenchymal transition. Urology 83: 1441-1443, 2014.

25. Li Z, Tian T, Lv F, Chang Y, Wang X, Zhang L, Li X, Li L, Ma W, Wu J and Zhang M: Six 1 promotes proliferation of pancreatic cancer cells via upregulation of cyclin D1 expression. PLoS One 8: e59203, 2013.

26. Parker JS, Roe SM and Barford D: Crystal structure of a PIWI protein suggests mechanisms for siRNA recognition and slicer activity. EMBO J 23: 4727-4737, 2004.

27. Peters L and Meister G: Argonaute proteins: Mediators of RNA silencing. Mol Cell 26: 611-623, 2007.

28. Houwing S, Kamminga LM, Berezikov E, Cronembold D, Girard A, van den Elst H, Filippov DV, Blaser H, Raz E, Moens CB, et al: A role for Piwi and piRNAs in germ cell maintenance and transposon silencing in Zebrafish. Cell 129: 69-82, 2007.

29. Hall TM: Structure and function of argonaute proteins. Structure 13: 1403-1408, 2005.

30. Sana J, Faltejskova P, Svoboda M and Slaby O: Novel classes of non-coding RNAs and cancer. J Transl Med 10: 103, 2012.

31. Meister G and Tuschl T: Mechanisms of gene silencing by double-stranded RNA. Nature 431: 343-349, 2004.

32. Elbashir SM, Harborth J, Lendeckel W, Yalcin A, Weber K and Tuschl T: Duplexes of 21-nucleotide RNAs mediate RNA interference in cultured mammalian cells. Nature 411: 494-498, 2001.

33. Riedmann LT and Schwentner R: miRNA, siRNA, piRNA and argonautes: News in small matters. RNA Biol 7: 133-139, 2010.

34. Simon B, Kirkpatrick JP, Eckhardt S, Reuter M, Rocha EA, Andrade-Navarro MA, Sehr P, Pillai RS and Carlomagno T: Recognition of 2'-O-methylated 3'-end of piRNA by the PAZ domain of a Piwi protein. Structure 19: 172-180, 2011.

35. Liang D, Dong M, Hu LJ, Fang ZH, Xu X, Shi EH and Yang YJ: Hiwi knockdown inhibits the growth of lung cancer in nude mice. Asian Pac J Cancer Prev 14: 1067-1072, 2013.

36. Liang D, Dong M, Hu LJ, Fang ZH, Xu X, Shi EH and Yang YJ: Hiwi knockdown inhibits the growth of lung cancer in nude mice. Asian Pac J Cancer Prev 14: 1067-1072, 2013.

37. Liang D and Shi Y: Aldehyde dehydrogenase-1 is a specific marker for stem cells in human lung adenocarcinoma. Med Oncol 29: 633-639, 2012. 